\title{
PcchiB1, encoding a class $V$ chitinase, is affected by PcVelA and PcLaeA, and is responsible for cell wall integrity in Penicillium chrysogenum
}

Correspondence

Ulrich Kück

ulrich.kueck@rub.de

Received 9 June 2011

Revised 1 August 2011

Accepted 2 August 2011
Jens Kamerewerd, ${ }^{1}$ Ivo Zadra, ${ }^{2}$ Hubert Kürnsteiner ${ }^{2}$ and Ulrich Kück ${ }^{1}$

${ }^{1}$ Christian Doppler Laboratory for 'Fungal Biotechnology', Lehrstuhl für Allgemeine und Molekulare Botanik, Ruhr-Universität Bochum, Universitätsstraße 150, 44780 Bochum, Germany

${ }^{2}$ Anti Infectives Microbiology, Sandoz GmbH, Biochemiestraße 10, 6250 Kundl, Austria

Penicillin production in Penicillium chrysogenum is controlled by PcVelA and PcLaeA, two components of the regulatory velvet-like complex. Comparative microarray analysis with mutants lacking PcVelA or PcLaeA revealed a set of 62 common genes affected by the loss of both components. A downregulated gene in both knockout strains is PcchiB1, potentially encoding a class V chitinase. Under nutrient-depleted conditions, transcript levels of PcchiB1 are strongly upregulated, and the gene product contributes to more than $50 \%$ of extracellular chitinase activity. Functional characterization by generating PcchiB1-disruption strains revealed that $\mathrm{PcChiB} 1$ is responsible for cell wall integrity and pellet formation in $P$. chrysogenum. Further, fluorescence microscopy with a DsRed-labelled chitinase suggests a cell wall association of the protein. An unexpected phenotype occurred when knockout strains were grown on media containing $\mathrm{N}$-acetylglucosamine as the sole $\mathrm{C}$ and $\mathrm{N}$ source, where, in contrast to the recipient, a penicillin producer strain, the mutants and an ancestral strain show distinct mycelial growth. We discuss the relevance of this class $\mathrm{V}$ chitinase for morphology in an industrially important fungus.

\section{INTRODUCTION}

Penicillium chrysogenum is the main industrial producer of the $\beta$-lactam antibiotic penicillin. In this filamentous ascomycete, developmental processes and secondary metabolism are tightly linked and controlled by diverse conserved regulators. Among these are PcVelA and PcLaeA, two global regulators, which have recently been shown to control penicillin biosynthesis as well as hyphal and conidiophore morphogenesis (Hoff et al., 2010a). Homologues of both proteins have been intensively studied in the model fungus Aspergillus nidulans (Calvo, 2008; Bok \& Keller, 2004; Sarikaya Bayram et al., 2010). For example, it has been shown that both proteins, together with VelB, form the core of a regulatory heterotrimeric complex, which we refer to as the velvet complex (Bayram et al., 2008a). The general regulatory function of these proteins is highly conserved in diverse filamentous fungi (Calvo, 2008), and it has been shown that velvet-like complexes exist in other ascomycetes (Hoff et al., 2010a; Wiemann et al., 2010).

Abbreviation: qRT-PCR, quantitative RT-PCR.

Seven supplementary figures and four supplementary tables are available with the online version of this paper.

The microarray data discussed in this paper are available from the NCBI Gene Expression Omnibus (GEO) under accession number GSE18585.
Despite its importance for development and secondary metabolism, so far only a few high-throughput transcriptional analyses have been conducted with strains lacking components of the velvet complex. Cary et al. (2007) performed a microarray analysis with a $\Delta v e A$ mutant of Aspergillus flavus to analyse the expression levels of 5002 genes. That study identified 136 differentially regulated genes in the disruption strain compared with the control strain, some of these representing known aflatoxin biosynthetic genes. In Aspergillus fumigatus, about $20-40 \%$ of all secondary metabolite biosynthesis genes are negatively affected by the loss of laeA, as detected by whole-genome microarray analysis (Perrin et al., 2007).

Using a PcvelA knockout strain, our previous microarray study to understand the expression profile of various genes involved in secondary metabolism and morphogenesis identified 1771 genes up- or downregulated in P. chrysogenum (Hoff et al., 2010a).

In this study, we present a follow-on microarray analysis with a knockout PclaeA mutant to identify genes collectively affected by the loss of both regulator proteins, PcVelA and PcLaeA. By this approach, we identified Pc22g01100, which encodes a putative class $\mathrm{V}$ chitinase, as being strongly downregulated in $\triangle$ PcvelA and $\triangle$ PclaeA mutant strains.

Chitinases (EC 3.2.1.14) represent an important subgroup of cell wall-modifying enzymes and hydrolyse chitin 
randomly at internal sites to generate soluble, low-molecularmass chitooligomers. Further morphogenetic, autolytic and nutritional roles have been found for fungal chitinases (Adams, 2004; Gooday et al., 1992; Sahai \& Manocha, 1993). In a widely accepted model, chitinases are necessary for the plasticity of the fungal cell wall in a concerted action with chitin synthase and $\beta$-1,4-N-acetylglucosaminidase (Bartnicki-Garcia, 1973; Rast et al., 1991).

All fungal chitinases belong to the glycosyl hydrolase family 18 (GH18) (Seidl, 2008; Henrissat \& Bairoch, 1993), and some chitinases seem to have different biological functions, while others are redundant. The genomes of filamentous ascomycetes and basidiomycetes so far analysed contain multiple genes encoding predicted or characterized chitinases, which, according to their structural similarities and reaction mechanisms, can be divided into subclasses III (subclass B) and V (subclass A). Recently, based on phylogenetic analysis, a third subclass $C$, with similarity to killer toxins from Kluyveromyces lactis, has been described (Gruber et al., 2011; Seidl, 2008; Seidl et al., 2005).

Several groups have reported disruption strains that lack distinct genes for diverse class $\mathrm{V}$ chitinases. However, most of these reports showed that the corresponding mutants have no apparent morphological phenotype. Because of its strong downregulation in both knockout strains, we wanted to determine whether Pc22g01100 is functionally responsible for some of the described phenotypes observed in $\triangle$ PcvelA and $\triangle$ PclaeA mutants.

Here, we provide a detailed functional analysis of Pc22g01100, which according to its homology to related fungal chitinase genes was named PcchiB1. Using PcchiB1 knockout mutants and rescued strains for a functional analysis, we observed significant morphological and physiological phenotypes. So far, these phenotypes are distinct from comparable chitinase knockout strains of other filamentous fungi.

\section{METHODS}

Strains and culture conditions. Escherichia coli strain XL1-Blue MRF $^{\prime}$ was used for general plasmid construction and maintenance (Jerpseth et al., 1992). Cloning and propagation of nucleic acids were performed using standard protocols according to Sambrook \& Russell (2001). The P. chrysogenum strains used in this study are listed in Table 1. All P. chrysogenum cultures were grown, unless otherwise stated, in baffled shake flasks with liquid minimal medium (MM), complete medium (CCM) and production medium at $27{ }^{\circ} \mathrm{C}$ and 130 r.p.m., or on MM and CCM solid medium containing $2 \%$ (w/v) agar-agar, as described elsewhere (Haas et al., 1997; Minuth et al., 1982). For fluorescence microscopic investigations, P. chrysogenum was grown in static liquid CCM cultures for $1-2$ days at $27^{\circ} \mathrm{C}$. For quantitative RT-PCR (qRT-PCR) analysis, strains were grown as previously described (Hoff et al., 2010b). All liquid media were inoculated with $10^{8}$ conidiospores. For point inoculations, $10^{5}$ spores were spotted on solid MM with or without $2 \%(w / v) ~ N$-acetyl-Dglucosamine (AppliChem).

Transformation of $\boldsymbol{P}$. chrysogenum. Transformation of linear restriction fragments and circular plasmids into P. chrysogenum was performed according to Hoff et al. (2010b), with some modifications: solid MM containing $5 \%(\mathrm{w} / \mathrm{v}) \mathrm{KCl}$ or $20 \%(\mathrm{w} / \mathrm{v})$ sucrose was used to regenerate protoplasts transformed with the ptrA selection marker from Aspergillus oryzae (Kubodera et al., 2000). At $24 \mathrm{~h}$ after transformation, the medium was overlaid with $11 \mathrm{ml}$ top agar containing $0.7 \mu \mathrm{g}$ pyrithiamine $\mathrm{ml}^{-1}$. Germinating protoplasts were transferred onto solid MM supplemented with pyrithiamine $(0.7 \mu \mathrm{g}$ $\mathrm{ml}^{-1}$ ) as a selectable substrate. To obtain homokaryotic deletion mutants, single spore isolates were selected and further analysed.

Preparation and analysis of nucleic acids. Preparation of nucleic acids, hybridization of membrane-transferred genomic DNA and total RNA, microarray analysis, PCR and qRT-PCR were carried out as previously described (Hoff et al., 2010b).

In silico sequence analysis. The sequence of $P c 22 g 01100$ published by van den Berg et al. (2008) served as template for further analysis (accession no. AM920437). In silico prediction of the translation initiation site of PcchiB1 was performed with the deduced cDNA sequence using the web interface of the NetStart 1.0 server (http:// www.cbs.dtu.dk/services/NetStart/; Pedersen \& Nielsen, 1997). The SignalP 3.0 server (http://www.cbs.dtu.dk/services/SignalP/; Bendtsen et al., 2004) was used to predict signal peptides, and functional domains of the PcChiB1 protein were determined by Interproscan (Zdobnov \& Apweiler, 2001). Multiple protein sequences were aligned with CLUSTAL_X (Thompson et al., 1997) by changing the gap opening penalty to the value of 15.00 and the gap extension penalty to 0.3 combined with $25 \%$ in the 'delay divergent sequences' option. Alignments were edited and analysed with GeneDoc (Nicholas et al., 1997). Phylogenetic analysis was performed with 1000 bootstraps using the maximum-parsimony method implemented in PHYLIP (Felsenstein, 2005). qRT-PCR analysis was conducted with Opticon Monitor 3.1 software as provided by the manufacturer (MJ Research) and LinRegPCR (Ruijter et al., 2009). Microarray data

Table 1. Fungal strains used in this study

\begin{tabular}{|c|c|c|}
\hline Strain & Genotype & Reference or source \\
\hline P2niaD18 & niaD ${ }^{-}$ & Hoff et al. (2008) \\
\hline$\Delta$ Pcku70 & $\Delta$ Pcku70::nat1; niaD ${ }^{-}$ & Hoff et al. (2010b) \\
\hline Q176 & Mutagenized derivative of strain NRRL1951 & Backus et al. (1946) \\
\hline Wisconsin $54-1255$ & Mutagenized derivative of strain Q176 & Elander (1983) \\
\hline$\Delta$ PcchiB1m9 & $\Delta$ PcchiB1::ble; $\triangle$ Pcku70:: nat $1 ;$ niaD ${ }^{-}$ & This study \\
\hline$\Delta$ PcchiB1m22-re & $\Delta$ PcchiB1:: ble; $\Delta$ Pcku70:: nat1; niaD ${ }^{-}$; PgdA::PcchiB1-DsRed::TtrpC, ptrA & This study \\
\hline
\end{tabular}


were analysed as previously described by Hoff et al. (2010b). Heat maps of expression data and cladograms were generated with TreeView (Page, 1996).

Chitinase assay. To detect extracellular chitinase activity, six biological replicates were grown for 240 and $312 \mathrm{~h}$ in $\mathrm{MM}$ at 130 r.p.m. and $27{ }^{\circ} \mathrm{C}$. After filtering cultures, three aliquots of each culture medium were taken to determine the amount of secreted proteins, quantified by the Bradford assay (Bradford, 1976). The chitinase assay was performed according to Lopes et al. (2008) with the dye-labelled chitin derivative CM-chitin-RBV (Loewe Biochemica; Wirth \& Wolf, 1990). Extracellular chitinase activity was assayed photometrically at $550 \mathrm{~nm}$ with a DU 7400 spectrophotometer (Beckman). The specific chitinase activity was measured as $A_{550}$ ( $\mu \mathrm{g}$ secreted protein) $)^{-1}$ according to Pócsi et al. (2009).

Microscopic analysis. Pellet formation was analysed in cultures grown in MM at 130 r.p.m. and $27{ }^{\circ} \mathrm{C}$ for 240 and 312 h. Bright-field images were taken with a Leica MZ16FA stereomicroscope using the Leica Application Suite 2.0 software (Leica Microsystems). Measurement of pellet size was carried out with an Olympus SZX10 stereomicroscope (Olympus Europa) and ImageJ (http://rsbweb.nih. gov/ij/; National Institutes of Health). Fluorescence microscopic investigation was performed with an AxioImager microscope (Carl Zeiss MicroImaging) using a XBO75 Xe or HBO100 Hg lamp for fluorescence excitation. Calcofluor white and filipin staining was observed using Chroma filter set 31000v2 (Chroma Technology). DsRed fluorescence was visualized with Chroma filter set 41035 (Chroma Technology). For cell wall staining of P. chrysogenum, samples were incubated for $5 \mathrm{~min}$ with $100 \mu \mathrm{g} \mathrm{ml}{ }^{-1}$ calcofluor white (Fluorescent Brightener 28, Sigma-Aldrich) prior to microscopic investigation. The cell membrane of $P$. chrysogenum was stained with filipin (filipin III, Sigma-Aldrich), applied to the sample at a final concentration of $1 \mu \mathrm{g} \mathrm{ml}^{-1}$. Images were captured with a Cool SnapHQ camera (Photometrics) and MetaMorph software (version 6.3r6, Molecular Devices). Recorded images were processed with MetaMorph and Adobe Photoshop CS4.

Calcofluor assay. Solid (MM) was supplemented with calcofluor white (Fluorescent Brightener 28, Sigma-Aldrich) to a final concentration of $200 \mu \mathrm{g} \mathrm{ml}^{-1}$. From a series of 10 -fold dilutions derived from a starting suspension of $10^{7}$ conidia $\mathrm{ml}^{-1}$, aliquots of $10 \mu \mathrm{l}$ were spotted on solid medium and incubated for 4 days.

Construction of PcchiB1 disruption strains. The sequences and specificities of all oligonucleotides used in this study are given in Supplementary Table S1. To construct a PcchiB1-specific knockout cassette, the $5^{\prime}$ and $3^{\prime}$ flanking regions of PcchiB1 were amplified by PCR using genomic DNA from P2niaD18 (Table 1) as a template. Primers 5'ChiB1_MluI and 5'ChiB1_BamHI were used for amplification of the $5^{\prime}$ flanking region containing a linker for $M l u \mathrm{I}$ and BamHI endonucleases, resulting in an amplicon of $1.9 \mathrm{~kb}$. The $1.9 \mathrm{~kb}$ $3^{\prime}$ flanking region of $P c c h i B 1$ was amplified with the oligonucleotides 3'ChiB1_XbaI and 3'ChiB1_HindIII (Supplementary Table S1). Both PCR fragments were subcloned in pDrive (Supplementary Table S2; Qiagen). Subsequently, both fragments were cloned via $M l u \mathrm{I}$ and BamHI (5' flanking region) or XbaI and HindIII ( $3^{\prime}$ flanking regions) into plasmid pD-Phleo (Hoff et al., 2010b). The resulting recombinant plasmid, pPcchiB1-KO (Supplementary Table S2), carrying the ble gene adjacent to the $5^{\prime}$ and $3^{\prime}$ flanks of the PcchiB1 locus, was cleaved

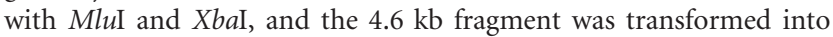
$\Delta$ Pcku70 (Table 1).

Rescue of PcchiB1 disruption strains. For complementation analysis, $\Delta$ PcchiB1m22 was transformed with plasmid pPcchiB1DsRed encoding the PcChiB1 protein fused with DsRed at its $\mathrm{C}$ terminus (Supplementary Table S2). For efficient expression, the strong constitutive $g p d A$ promoter and the $\operatorname{trp} C$ terminator from $A$. nidulans (Punt et al., 1990; Mullaney et al., 1985) were used to express the recombinant construct.

\section{RESULTS}

\section{Comparative array analysis}

We recently reported a microarray analysis using $\triangle$ PcvelA and its recipient $\Delta \mathrm{Pcku} 70$ for comparison, which identified 1771 genes that were differentially regulated in $\triangle \mathrm{PcVelA}$ (Hoff et al., 2010a). Here, in a similar comparative experimental approach with $\Delta$ Pcku70 as a reference strain, we used microarrays to identify sequences affected by the loss of PcLaeA. Isolation of mRNA was performed from a $\triangle$ PclaeA knockout mutant grown on production medium for 48, 60 and $96 \mathrm{~h}$. Considering a twofold change in expression levels as a threshold, we found a total of 1282 down- and 789 upregulated genes (Supplementary Fig. S1). Comparable with our previous report for the $\triangle$ PcvelA mutant, penicillin biosynthetic genes were downregulated after 60 and $96 \mathrm{~h}$ of growth (Hoff et al., 2010a), while other genes for secondary metabolism showed less consistent mRNA levels (Fig. 1a).

However, we found a number of genes involved in conidiophore development that showed significantly altered mRNA levels, which is in agreement with our identification of PcLaeA as a main regulator of conidiophore development in P. chrysogenum (Fig. 1b; Hoff et al., 2010a). We further detected reduced expression levels of five transcripts encoding putative class III or $\mathrm{V}$ chitinases in the $\Delta$ PclaeA strain. While the transcripts of the class III chitinases Pc22g13690 and Pc21g15780 were reduced after 60 and $96 \mathrm{~h}$ of growth, the expression levels of genes encoding the class $\mathrm{V}$ chitinases Pc22g01100, Pc13g09520 and Pc20g02250 were downregulated at every time point analysed (Fig. 1c, Supplementary Table S3). For Pc22g01100, the decreased mRNA level was confirmed by qRT-PCR analysis (Fig. 1d).

To identify genes affected by the loss of both PcvelA and PclaeA, we compared array data obtained previously (Hoff et al., 2010a) with that obtained in this study from the corresponding knockout mutants. The transcriptome analysis showed rather small overlaps of 46 down- and 16 upregulated genes (Fig. 2). Interestingly, BLAST analysis of these sequences revealed that a relative high number of genes presumed to encode $\mathrm{C} 6$ zinc cluster transcription factors are found in the group of downregulated sequences (Supplementary Table S4). Notably, the overlap also includes Pc22g01100, which shows 13- to 79-fold and 51- to 86-fold reduced transcript levels in $\triangle \mathrm{PclaeA}$ and $\triangle \mathrm{PcvelA}$, respectively (Supplementary Table S3; Hoff et al., 2010a).

\section{Sequence analysis of gene Pc22g01100}

In the published P. chrysogenum genome, Pc22g01100 is annotated as a putative pseudogene with an undefined start codon (accession no. AM920437; van den Berg et al., 
(a)

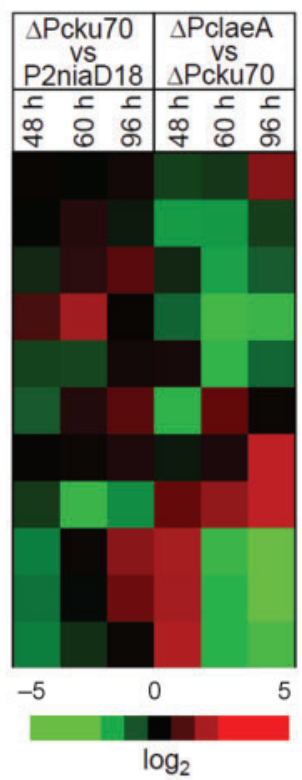

(c)

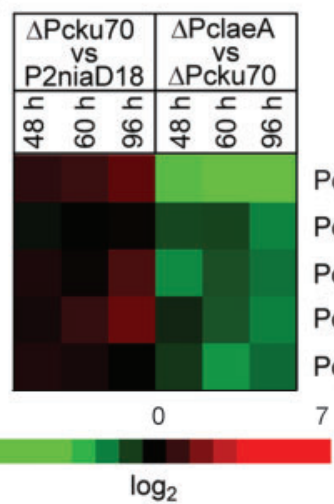

7 (b)

Pc12g13170 NRPS-like

Pc21g01710 NRPS

Pc21g12630 NRPS

Pc21g16000 PKS

Pc21g05080 PKS

Pc16g11480 PKS

Pc21g04840 PKS

Pc21g00960 PKS

Pc21g21390 pcbAB

$\mathrm{Pc} 21 \mathrm{~g} 21380 \mathrm{pcbC}$

Pc21g21370 penDE

Pc22g01100 class $V$ chitinase

Pc13g09520 class $V$ chitinase

Pc20g02250 class $V$ chitinase

Pc22g13690 class III chitinase

Pc21g15780 class III chitinase
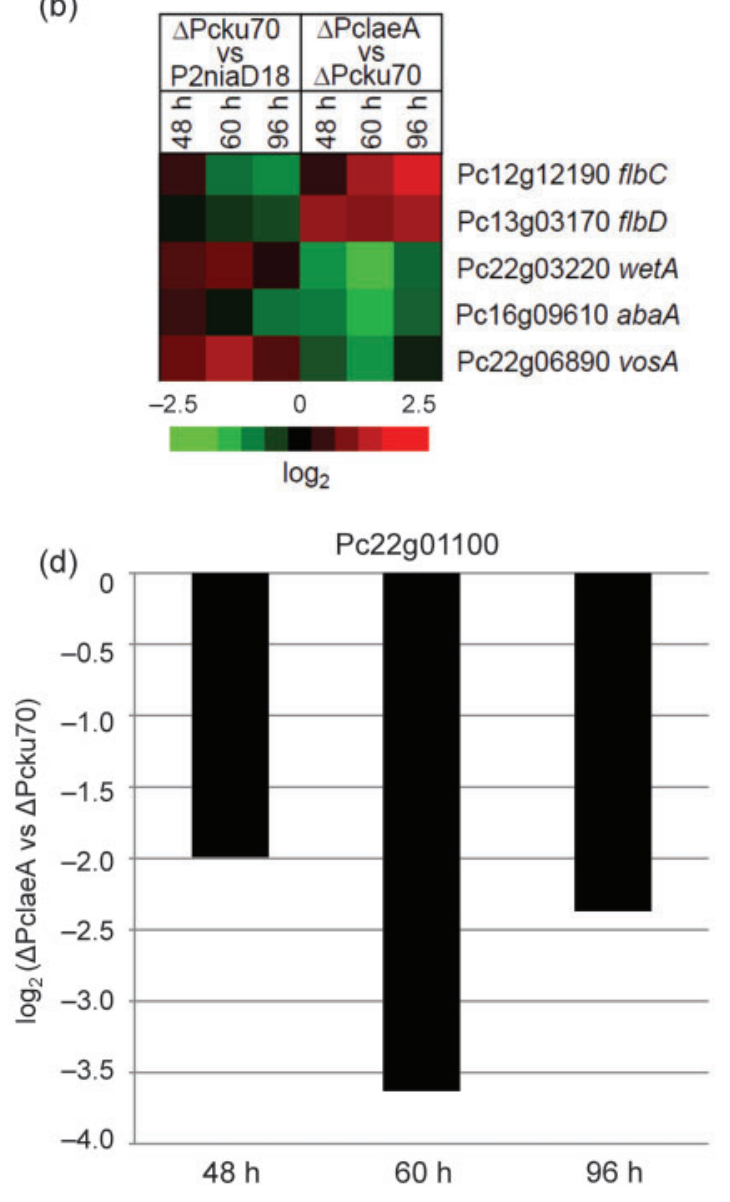

Fig. 1. Expression levels of transcripts affected by the loss of PcLaeA. The heat maps $(a-c)$ illustrate data from microarray analysis of $\triangle$ PclaeA. Transcripts encoding proteins involved in secondary metabolism (a), conidiophore development (b) and chitinases (c) were analysed. Red squares indicate upregulation of gene expression, green squares downregulation. The colour of each square represents the $\log _{2}$ fold change in expression levels at a given time point. (d) The transcript level of gene Pc22g01100 as determined by qRT-PCR analysis. At the given time points, $\log _{2}$ ratios of expression levels compared with the recipient $\Delta \mathrm{Pcku} 70$ are shown.

2008). Thus, to identify a potential ATG start codon, we generated a cDNA clone for further sequencing of the ORF. In silico analysis with the NetStart 1.0 prediction server (Pedersen \& Nielsen, 1997) identified two putative
ATG start codons within the ORF. The ATG triplet at nucleotide position 301 is the most probable start site of translation (data not shown), and the corresponding annotation of the Pc22g01100 coding sequence predicts a
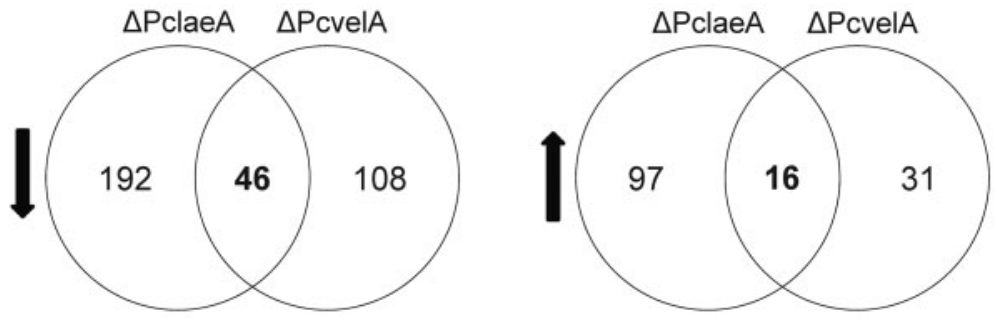

Fig. 2. Venn diagrams of differentially regulated genes in $\triangle \mathrm{Pclae} A$ and $\triangle \mathrm{Pcvel} A$. Only genes which were differentially expressed at all time points (48, 60 and $96 \mathrm{~h}$ ) were considered. The number of genes in common is given in bold type in the intersection. 
protein of 427 aa with an estimated molecular mass of $47 \mathrm{kDa}$.

The identity of the predicted Pc22g01100 protein was further confirmed by alignment with putative homologous proteins (Supplementary Fig. S2). The protein most similar to $\mathrm{Pc} 22 \mathrm{~g} 01100$ is a putative class $\mathrm{V}$ chitinase from $P$. chrysogenum, Pc13g00130 (accession no. CAP91082.1), sharing $68 \%$ amino acid identity with Pc22g01100. In addition, chitinases ChiB1 from $A$. fumigatus (XP_747065.1) and CTS1 from Coccidioides immitis (Q1E3R8.1), with 62 and $57 \%$ identity with Pc22g01100, respectively, were considered orthologous sequences (Supplementary Fig. S2).

Comparison of these four chitinases with homologous chitinases from Hypocrea jecorina (chitinase 18-7, accession no. DAA05855.1), A. nidulans (ChiB, XP_662475.1), P. chrysogenum (Pc13g09520, CAP92021.1) and A. fumigatus (AFUB_037900, EDP52624.1) revealed a lack of N-terminal sequences in this second group (Supplementary Fig. S2).

As indicated by in silico analysis, the $\mathrm{N}$-terminal sequence of Pc22g01100 most likely represents a putative signal peptide for secretion, which is in accordance to the extracellular localization of $\mathrm{Pc} 22 \mathrm{~g} 01100$ predicted by WoLF PSORT (Horton et al., 2007). Considering the high similarity of Pc22g01100 to chitinase ChiB1 from A. fumigatus (Escott et al., 1998), its gene was named PcchiB1.

Using the maximum-parsimony method implemented in PHYLIP (Felsenstein, 2005), we performed a phylogenetic analysis using the predicted protein sequence of PcChiB1 together with six other putative class $\mathrm{V}$ chitinases of $P$. chrysogenum listed in the CAZy database (Cantarel et al., 2009). The phylogenetic tree in Fig. 3 confirms the close relationships with other chitinases, as was predicted from the alignment (Supplementary Fig. S2). Interestingly, ChiB, a well-characterized chitinase from $A$. nidulans (Yamazaki et al., 2007) locates together with related sequences in a sister clade; the four other class $\mathrm{V}$ chitinases from $P$. chrysogenum (Pc14g01550, Pc16g15030, Pc20g02250 and Pc22g25160) are less closely related to PcChiB1.

\section{Analysis of PcchiB1 transcript levels and chitinase activity}

We used $\Delta$ Pcku70 (Hoff et al., 2010b) as a recipient for homologous recombination to construct a PcchiB1 deletion strain. The screening of 18 primary bleomycin-resistant transformants by PCR analysis using primers ChiB1_for_N and ChiB1_rev_N (Supplementary Table S1) with specificity for the PcchiB1 gene resulted in a specific amplicon of $402 \mathrm{bp}$ for each transformant (data not shown). Two of these independently obtained transformants were selected to isolate homokaryotic strains from single spore isolates. The resulting mutant strains lacking the PcchiB1-specific amplicon were designated $\mathrm{m} 9$ and $\mathrm{m} 22$. Southern analysis confirmed that no additional recombinant DNA was present in the nuclear DNA of either mutant (Supplementary Fig. S3).

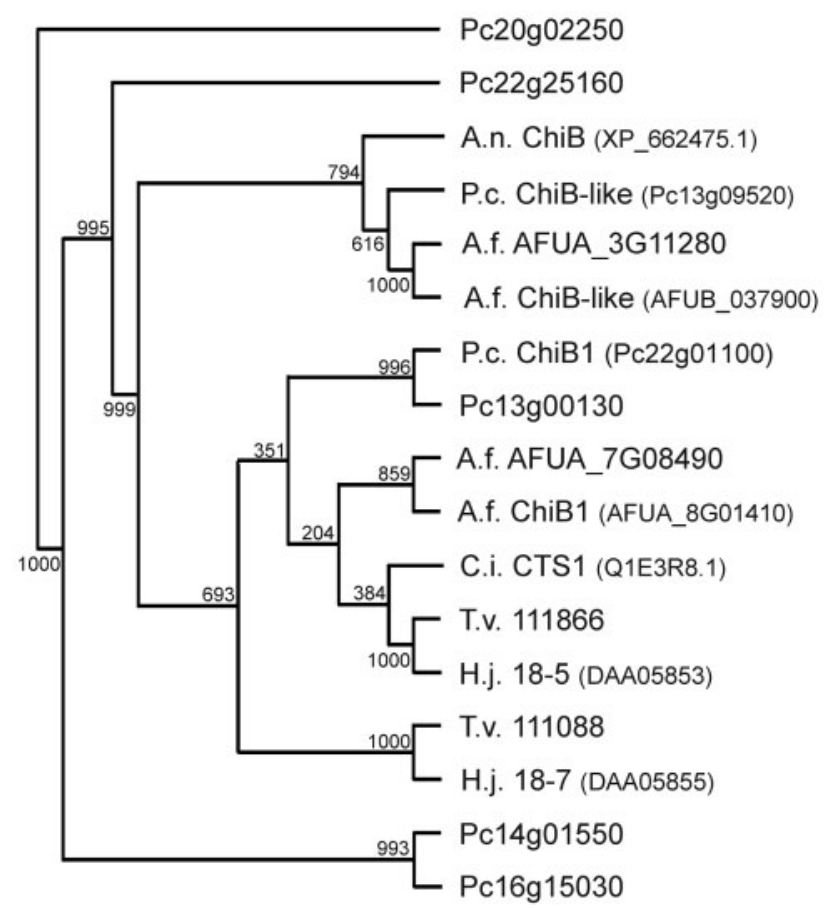

Fig. 3. Phylogenetic tree of class $V$ chitinases from $P$. chrysogenum (P.c. or $\mathrm{Pc}+$ sequence identifier), A. nidulans (A.n.), $A$. fumigatus (A.f.), C. immitis (C.i.), Trichoderma virens (T.v.) and $H$. jecorina (H.j.). For $P$. chrysogenum, sequence identifiers were used according to van den Berg et al. (2008). A. fumigatus and $T$. virens chitinases are listed by protein models of the corresponding databases. Protein sequences of $A$. nidulans, $C$. immitis and $H$. jecorina are represented by GenBank accession numbers. The tree was calculated by the maximum-parsimony method with 1000 bootstrap replicates. Bootstrap values are given for each node.

For characterization of PcchiB1 transcript levels and chitinase activity in the disruption mutants $\triangle$ PcchiB $1 \mathrm{~m} 9$ and $\Delta$ PcchiB $1 \mathrm{~m} 22$, recipient $\Delta$ Pcku70 with a deleted $P c k u 70$ gene for efficient gene replacement (Hoff et al., 2010b) and its ancestor, the penicillin producer P2niaD18 (Hoff et al., 2008), served as control strains (Table 1). Northern analysis revealed that the PcchiB1-specific transcript accumulated significantly after $312 \mathrm{~h}$ of growth in the reference strain P2niaD18 and the recipient $\Delta$ Pcku70, whereas no transcript was detected in either knockout strain (Fig. 4).

We further analysed chitinase activity in the supernatant of all strains investigated, and detected about $50 \%$ less extracellular chitinase activity in the knockout mutants after 240 and $312 \mathrm{~h}$ of growth in MM (Fig. 5). Intracellular chitinase activity was generally lower for each strain and did not exceed $25 \%$ of extracellular activity (data not shown). These results demonstrate that PcChiB1 contributes to most of the extracellular chitinase activity in $P$. chrysogenum. 


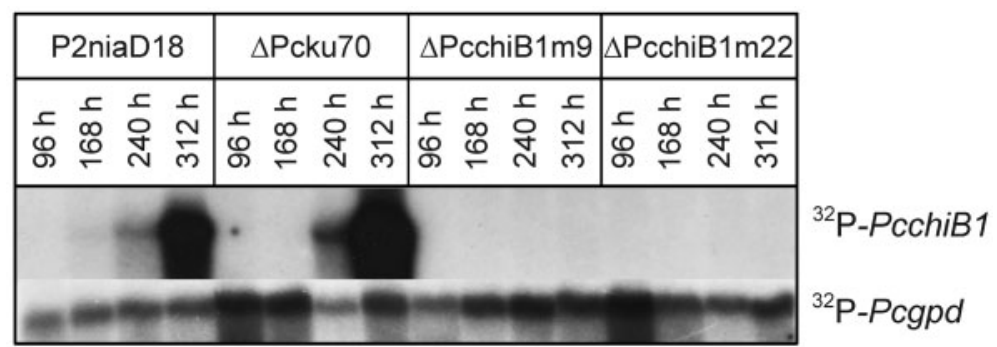

Fig. 4. Northern analysis of $P_{c c h i B} 1$ transcript levels. At the indicated time points RNA was isolated from cultures grown in liquid MM. As a control, the Pcgpd gene with a constitutive expression level was analysed.

\section{Phenotypic characterization of the disrupted PcchiB1 strains}

When the control and mutant strains were grown on solid CCM, we observed no aberrant mutant phenotype compared with the recipient $\Delta$ Pcku70 and P2niaD18. However, when the knockout strains were grown in nutrient-depleted MM for more than $240 \mathrm{~h}$, we detected stable pellet formation in submerged cultures, as characterized by highly entangled, densely packed hyphae. The control strains P2niaD18 and $\Delta$ Pcku70 lost this compact mycelial morphology after growth for more than $240 \mathrm{~h}$, resulting in highly fragmented and dispersed hyphae with the formation of only a few small fringed pellets (Fig. 6).

In contrast, $\Delta \mathrm{PcchiB} 1 \mathrm{~m} 9$ and $\Delta \mathrm{PcchiB} 1 \mathrm{~m} 22$ retained the pellet morphology for a growth period of at least $312 \mathrm{~h}$ (Fig. 6). The pellet size from at least two biological replicates with a $\triangle P c k u 70$ or $\triangle P c c h i B 1$ background was quantified in submerged cultures with production medium. Both strains grew continuously as mycelial pellets with a pellet diameter of 190-220 $\mu \mathrm{m}$ over a period of 96-168 h (Supplementary Fig. S4). In $\Delta$ Pcku70, pellet size clearly decreased after prolonged growth for $240 \mathrm{~h}$, resulting in a mean diameter of $40 \mu \mathrm{m}$ per pellet. As expected from the microscopic analysis, the pellet size in $\Delta$ PcchiB1m22 decreased only slightly after $240 \mathrm{~h}$ of growth, when the mean pellet size was about $175 \mu \mathrm{m}$.

Our microscopic analyses and quantification of pellet sizes at different time points indicate that the pellet morphology of $\Delta$ Pcku70 is lost during prolonged growth, regardless of the media composition. In contrast the mutant's morphology remains constant over a period of $312 \mathrm{~h}$. Despite the obvious differences in morphology, the mutant and control strains show identical dry weight (data not shown).

\section{Modified cell wall composition of the disrupted PcchiB1 strains}

To analyse whether cell wall integrity was affected by the lack of PcChiB1, both mutants and the control strains were grown on solid MM containing calcofluor white, and as a control, on media lacking calcofluor. All strains exhibited equal conidial germination rates (Supplementary Fig. S5); therefore, restricted growth on calcofluor-containing medium indicates an altered cell wall composition. Different dilutions of conidia were inoculated for 4 days, and the growth of mutant mycelium was compared with mycelium from the parental strains. As can be seen in Fig. 7(a),

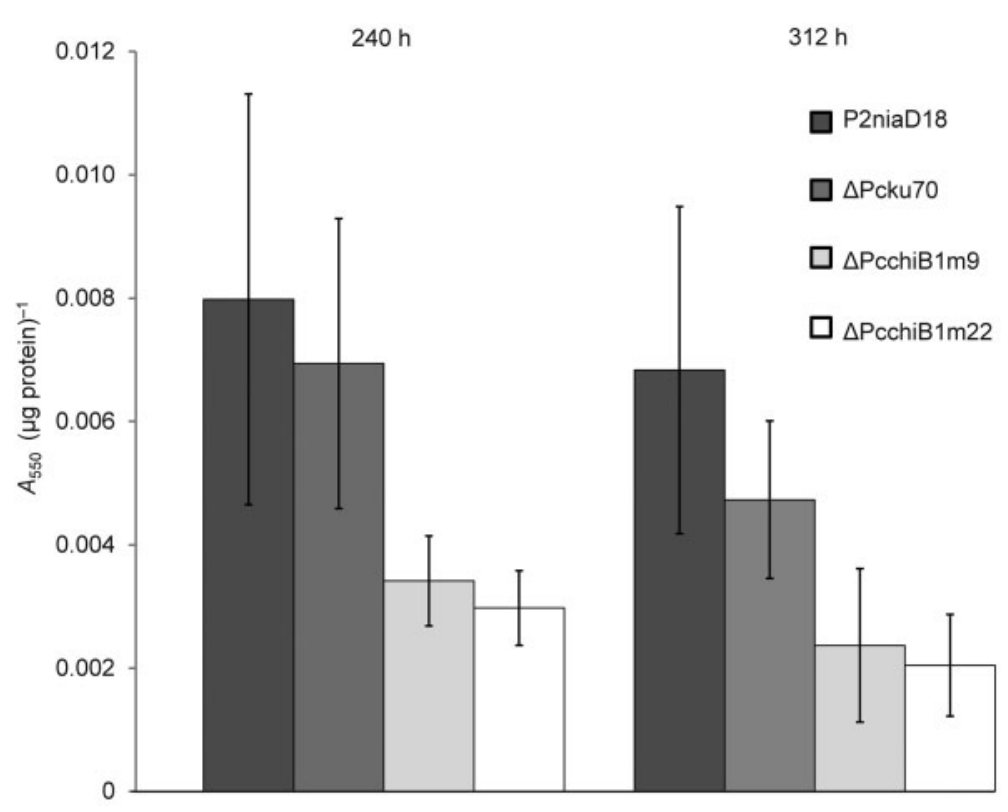

Fig. 5. Chitinase activity in the supernatant of cultures after 240 and $312 \mathrm{~h}$ of growth in MM. The chitinase activity of each strain was analysed with six biological replicates by the measurement of the $A_{550}$ per microgram of secreted protein. 


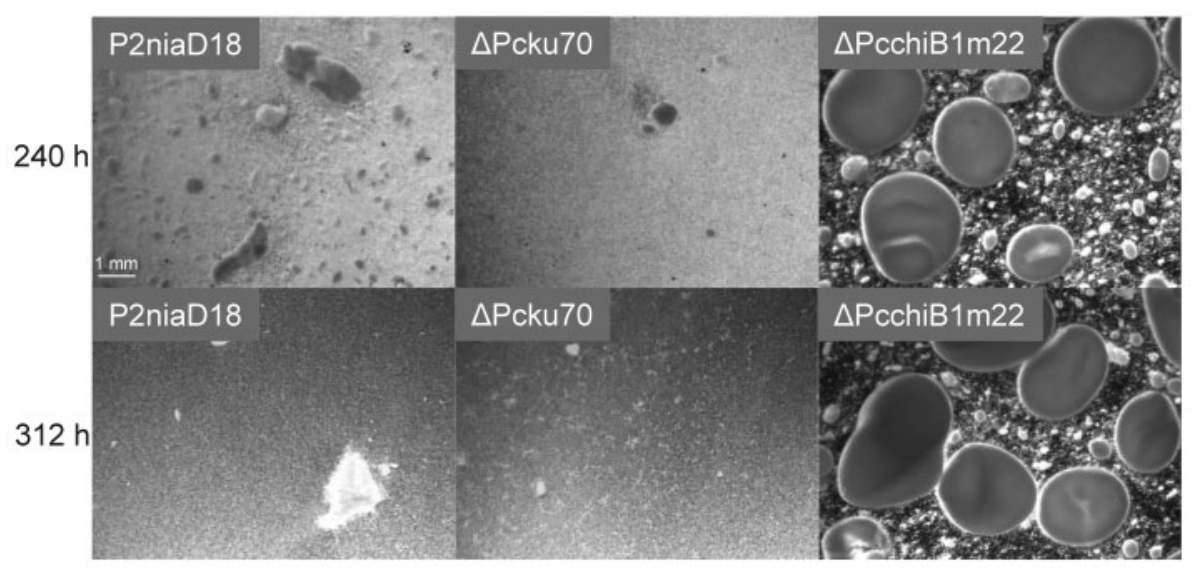

Fig. 6. Pellet formation of different strains in $M M$ at the indicated time points.

P2niaD18 and both mutants exhibited similar phenotypes on $\mathrm{MM}$, while the fitness of $\Delta \mathrm{Pcku} 70$, recently shown to be more stress sensitive than P2niaD18 (Hoff et al., 2010b), was slightly reduced. In contrast, growth of all strains was significantly reduced when cultivated on MM supplemented with calcofluor white. However, the two mutant strains were less affected than the control strains (Fig. 7a).

To confirm that the observed phenotype is due to deletion of PcchiB1, $\Delta$ PcchiB1m22 was rescued by reintroducing a
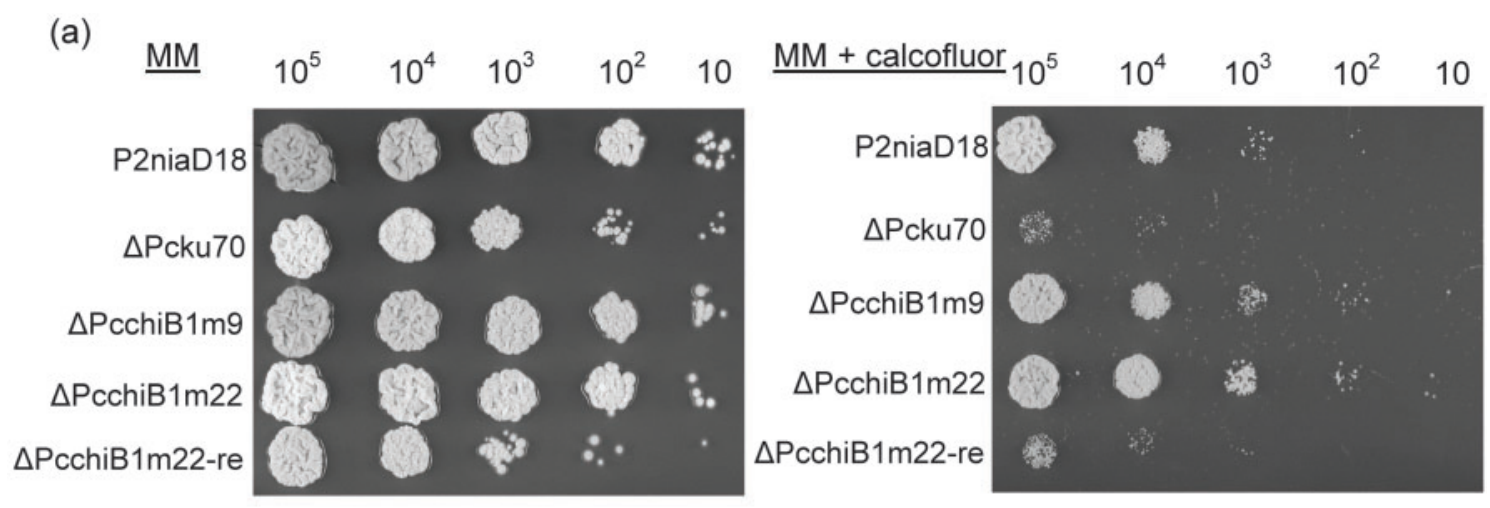

(b)
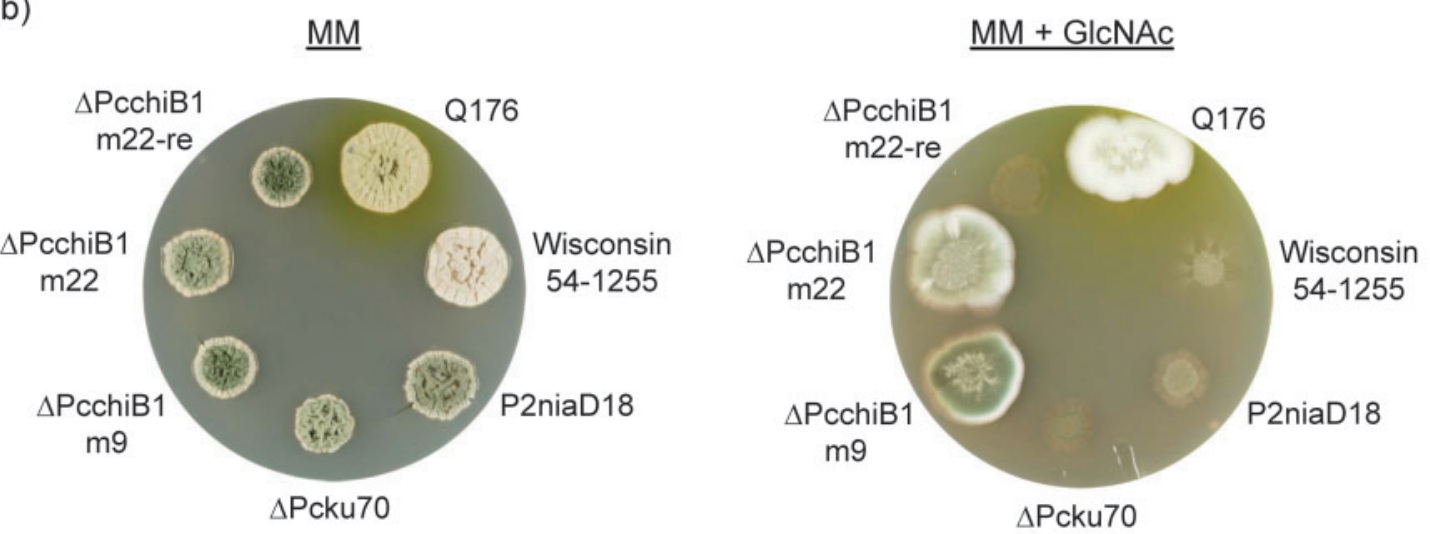

Fig. 7. Growth assays. (a) Cell wall integrity assay on MM supplemented with $200 \mu \mathrm{g}$ calcofluor white $\mathrm{ml}^{-1}$ and $\mathrm{MM}_{\mathrm{mithout}}$ calcofluor as a control. The indicated number of conidia was allowed to germinate for 4 days. (b) Growth characteristics of mutant strains on solid MM after 6 days and on medium with $2 \%(w / v)$ GlcNAc as sole carbon and nitrogen source after 12 days. 
plasmid encoding wild-type PcChiB1 fused to DsRed (pPcchiB1-DsRed, Supplementary Table S2). Successful reintegration of the recombinant PcchiB1 gene was verified by PCR (data not shown) and Southern analysis (Supplementary Fig. S3). The phenotype of the rescued strain $\triangle$ PcchiB1m22-re resembled that of the recipient strain $\Delta$ Pcku70. From this analysis we surmise that deletion of PcchiB1 results in a modified cell wall composition, thus generating mutants with increased resistance towards calcofluor. Remarkably, the microscopic analysis showed no obvious morphological differences when the mutant cell wall was stained with calcofluor white (Supplementary Fig. S6).

Since PcChiB1 represents the main extracellular chitinase activity in $P$. chrysogenum, we investigated fungal growth with colloidal chitin as sole carbon and nitrogen source. In addition, mutants were grown on solid or in liquid media containing the chitin monomer $\mathrm{N}$-acetylglucosamine (GlcNAc) as the sole $\mathrm{N}$ and $\mathrm{C}$ source. While with colloidal chitin we observed no growth differences compared with the control strains P2niaD18 and $\Delta$ Pcku70 (data not shown), a significant difference was seen with GlcNAc. The disruption strains showed distinct mycelial growth, whereas both control strains were unable to propagate even after prolonged incubation for 12 days (Fig. 7b). This analysis was further extended by testing the producer strain Wisconsin 54-1255 (Elander, 1983) and its ancestor Q176 (Backus et al., 1946). With both liquid and solid media, Q176 showed the same growth phenotype as the two mutant strains. In contrast, Wisconsin 54-1255, as well as the rescued strain $\Delta$ PcchiB1m22-re, were unable to use GlcNAc efficiently (Fig. 7b, Supplementary Fig. S7).

The ability of knockout strains to grow on GlcNAc was further analysed at the transcriptional level by Northern hybridization using two different probes with homology to either NAG1 from the yeast Candida albicans, Pc22g10040 (accession no. XM_002564967), or CreA from A. nidulans, Pc20g13880 (XM_002563820). NAG1 encodes a glucosamine-6-phosphate deaminase, and has previously been shown to be involved in GlcNAc catabolism (Natarajan \& Datta, 1993), whereas CreA represents a putative regulator of carbon catabolism. While no strain-specific transcript levels were detected for the NAG1 homologue (data not shown), the CreA probe showed a distinct strain-specific expression pattern, with increased expression levels in Q176 and both chitinase mutants compared with the recipient strain $\triangle$ Pcku70 (Fig. 8a). No CreA transcript was detected in the rescued mutant $\Delta$ PcchiB1m22-re (Fig. $8 b$ ) and in the penicillin producer strains Wisconsin 54-1255 and P2niaD18 (data not shown).

\section{Chitinase PcChiB1 is associated with the cell wall}

Furthermore, we studied the in vivo localization of PcChiB1 in the rescued strain $\triangle$ PcchiB1m22-re. As can be seen in Fig. 9, the recombinant PcChiB1 protein fused to DsRed was visible at vacuole-like structures and at the periphery of conidiospores or vegetative fungal cells. To discriminate between the cell wall and the cell membrane, we used the cell wall-staining dye calcofluor white (Elorza et al., 1983; Maeda \& Ishida, 1967) and the cell membranespecific dye filipin (Pearson et al., 2004; Takeshita et al., 2008). At septal structures, the two plasma membranes of the separated hyphal compartments were clearly distinguished by filipin staining, while the PcChiB1-DsRedspecific fluorescence was located between the membranes at the septum, indicating an association of PcChiB1 with the fungal cell wall (Fig. 9).

\section{DISCUSSION}

\section{Identification of common genes affected by PcLaeA and PcVelA, two core components of the velvet-like complex}

We recently described the velvet-like complex of the industrial $\beta$-lactam producer $P$. chrysogenum, which regulates asexual and hyphal development in $P$. chrysogenum. The disruption of genes for PcVelA and PcLaeA, two core elements of this complex, leads to significantly reduced penicillin titres caused by a strong transcriptional silencing of the penicillin biosynthetic gene cluster (Hoff et al., 2010a).

The phenotypes of $\Delta$ PcvelA and $\Delta$ PclaeA, such as altered hyphal branching and positive regulation of the penicillin biosynthetic genes, as well as their physical interaction, (a)

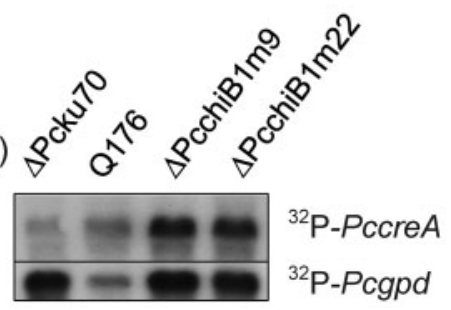

(b)

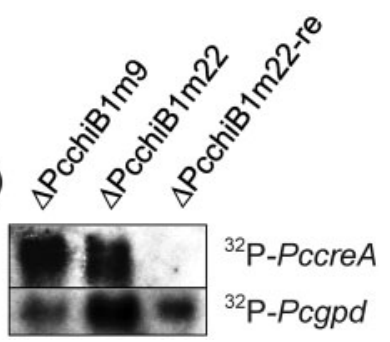

Fig. 8. Northern analysis of PccreA transcript levels in strains grown for 10 days in liquid MM with GlcNAc as sole carbon and nitrogen source. (a) Northern analysis of mutants $\Delta$ PcchiB1m9 and $-\mathrm{m} 22$ in comparison with recipient $\triangle$ Pcku70 and strain Q176. (b) Northern analysis of mutants $\triangle \mathrm{PcchiB} 1 \mathrm{~m} 9$ and $-\mathrm{m} 22$ in comparison with the rescued strain $\triangle$ PcchiB1m22-re. As a control, the Pcgpd gene with a constitutive expression level was analysed. 
(a)
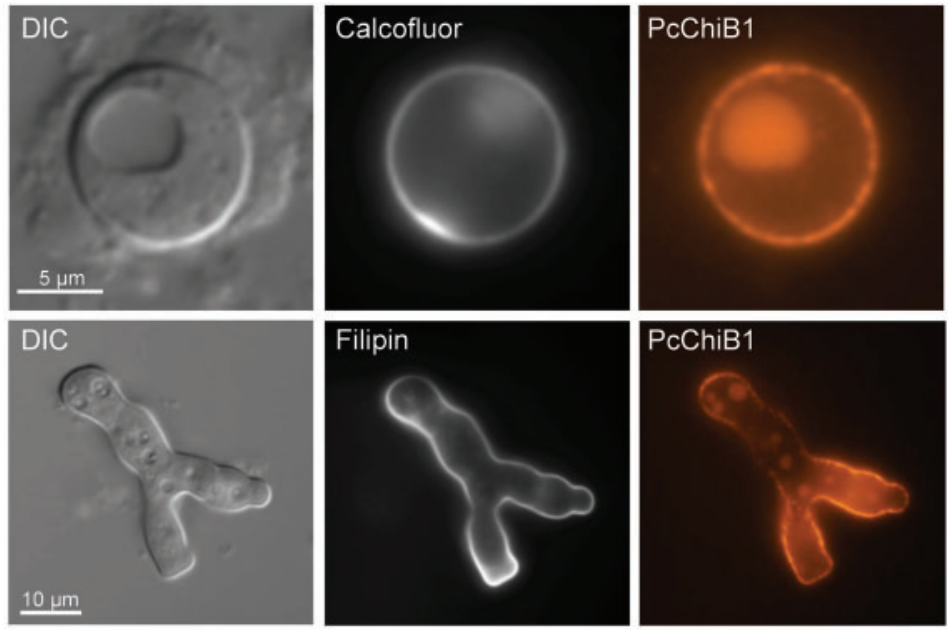

(b)

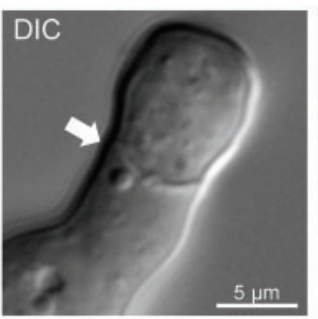

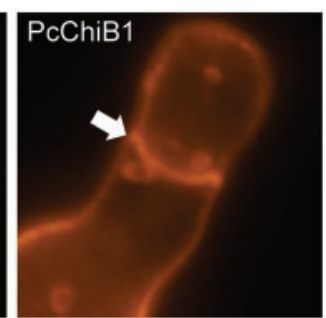

Fig. 9. Fluorescence microscopy of conidiospores and vegetative cells of $P$. chrysogenum. (a) Overview of condiospore and vegetative hypha. (b) Detail of cell wall and septum of a vegetative hypha. Samples were analysed by differential interference contrast (DIC) microscopy, stained with dyes (calcofluor, filipin) as indicated, or were investigated with a DsRedspecific filter set for detection of the PcChiB1DsRed fusion protein (PcChiB1). The arrows point to a septum. imply that both proteins directly or indirectly regulate a common subset of genes. We therefore compared previously reported microarray data for the $\triangle P c v e l A$ mutant (Hoff et al., 2010a) with data obtained here using the $\triangle$ PclaeA disruption strain.

To our knowledge, this is the first report from a comparative analysis of array data from two strains lacking main components of a velvet-like complex. This approach successfully identified genes concertedly influenced by the loss of both PcLaeA and PcVelA. One of the most downregulated genes in both knockout mutants was Pc22g01100, encoding a class V chitinase.

We recently reported a hyperbranching phenotype for $\Delta$ PcvelA and, to a lesser extent, for $\Delta$ PclaeA (Hoff et al., 2010a). In addition, $\Delta$ PcvelA showed an enhanced pellet formation in submerged cultivation. This was retained for a prolonged growth period, resulting in a higher dry weight compared with the control strain, and suggests a delay in autolysis. Furthermore, calcofluor staining revealed an enhanced fluorescence in the hyphal tips of $\Delta$ PcvelA, indicating increased chitin content in this region (Hoff et al., 2010a). A Neurospora crassa strain with a deleted homologue of VeA displays a slightly disturbed hyphal branching pattern on solid medium (Bayram et al., 2008b). Similarly, deletion of VeA homologues in Acremonium chrysogenum and Fusarium verticilloides causes altered hyphal branching, which is thought to be caused by cell wall defects (Dreyer et al., 2007; Li et al., 2006). Due to its strong downregulation in both knockout strains, we asked whether Pc22g01100 is functionally responsible for some of the described phenotypes observed in $\triangle$ PcvelA and $\triangle$ PclaeA.

\section{$\Delta$ PcchiB1 shows novel and distinct morphological and physiological phenotypes}

The PcchiB1 transcript is strongly induced when $P$. chrysogenum is grown for a prolonged period. More than 10 days of growth in batch cultures depletes nutrients, which suggests that PcchiB1 expression is induced by a lack of carbon and/or nitrogen sources. Increased transcript levels of PcchiB1 indicate a functional role for its gene product in degrading chitin from the fungal cell wall in order to supply the fungus with new nutritional resources. Similarly, increased expression levels have been reported for ech42, encoding the class V chitinase CHIT42 of Trichoderma atroviride and $C h i B$ from $A$. nidulans, when grown under various nutrient-depleted conditions (Donzelli \& Harman, 2001; Mach et al., 1999; Pócsi et al., 2009; Pusztahelyi et al., 2006; Seidl et al., 2005). Therefore, nutrient-dependent regulation of PchiB1 expression in $P$. chrysogenum is proposed to represent a conserved function common to various class $\mathrm{V}$ chitinases.

Consistent with PcchiB1 transcript levels, the overall extracellular chitinase activity detected in the supernatant of control and mutant strains increases during prolonged growth. However, after 10 days of growth, chitinase activity is reduced by about $50 \%$ in the disruption mutant, suggesting that PcChiB1 provides the major extracellular chitinase activity in $P$. chrysogenum under these conditions. 
Since PcchiB1 disruption strains exhibit residual extracellular chitinase activity, the remaining extracellular chitinases have to compensate for the lack of PcChiB1 in $P$. chrysogenum. This is in contrast with results obtained from A. fumigatus with a deleted ChiB1 gene. While after 6 days of growth the wild-type strain exhibits maximum extracellular chitinase activity, the disruption strain shows almost no residual chitinase activity (Jaques et al., 2003).

In $P$. chrysogenum, the maximum level of extracellular chitinase activity is accompanied by the onset of pellet disintegration in the two control strains, P2niaD18 and $\Delta$ Pcku70. Conversely, the reduced chitinase activity in both knockout strains, $\Delta$ PcchiB $1 \mathrm{~m} 9$ and $\Delta$ PcchiB1m22, correlates with stable pellet formation after prolonged growth, albeit that dry cell weight was identical in all strains investigated. This suggests that $\mathrm{PcChiB} 1$ is required for cell wall integrity. PcChiB1 seems thus to be responsible for the initial breakdown of hyphal structures, leading to the disintegration of pellets, but is not exclusively responsible for the complete lysis of fungal cell walls. The remaining extracellular chitinase activity detected in the autolytic cultures of the knockout mutants, and the presence of six other class $\mathrm{V}$ chitinases encoded in the genome, mean that further chitinases are likely involved in the lysis of $P$. chrysogenum cultures under nutrient-depleted conditions.

Similar results have been reported for A. nidulans, whereby strong induction of chitinase ChiB is observed in cultures starved for carbon sources (Pócsi et al., 2009; Pusztahelyi et al., 2006). In this fungus, the induction of gene expression is consistent with the increase in $\mathrm{ChiB}$ protein levels and extracellular activity, and correlates well with the observed pellet disintegration discussed above (Pócsi et al., 2009; Shin et al., 2009; Yamazaki et al., 2007). In contrast to the unaltered dry cell weight in PcchiB1 mutants of P. chrysogenum and a ChiB1 mutant of A. fumigatus (Jaques et al., 2003), deletion of ChiB in A. nidulans results in a slower decrease in mycelial dry weight in carbon-starved cultures. This is accompanied by an almost complete loss of extracellular chitinase activity (Pócsi et al., 2009; Shin et al., 2009; Yamazaki et al., 2007). However, since overexpression of $C h i B$ does not drive the reduction of dry cell weight, Shin et al. (2009) suggest that ChiB is necessary, but not sufficient, for autolysis in A. nidulans. In conclusion, it can be suggested that additional chitinases yet to be identified contribute to the autolytic process in response to nutrient depletion in P. chrysogenum, A. nidulans and A. fumigatus. This hypothesis is also supported by the observation that staining of hyphae of $\triangle P c c h i B 1$ mutants with the chitinintercalating fluorescent dye calcofluor white revealed wildtype-like fluorescence in the mutant cell wall, thus indicating that the PcchiB1 deletion does not cause a major change in the chitin content of the cell wall. However, when we used calcofluor white to analyse cell wall integrity, deletion of PcchiB1 conferred enhanced resistance to calcofluor white. We propose that hydrolysis of chitin microfibrils is reduced in the $\triangle$ PcchiB1 mutant. According to the chitin turnover model of Bartnicki-Garcia (1973), which requires a delicate balance of chitinases and chitin synthases to provide cell wall plasticity, a lower level of chitin hydrolysis results in a less severe interfering effect of calcofluor white due to lower chitin microfibril assembly rates. In agreement with the proposed role of PcchiB1 in the initial breakdown of hyphal structures, this would cause the higher resistance of the disruption mutants to calcofluor white, while the chitin content of their cell walls remains mainly unaltered.

Although the stable pellet formation observed for $\triangle \mathrm{PcchiB} 1$ in submerged cultures is reminiscent of the pellet morphology of $\Delta$ PcvelA (Hoff et al., 2010a), notable phenotypic differences concerning dry weight in submerged cultures and calcofluor staining of hyphae are obvious when the two strains are compared. The drastic decrease in transcript levels of PcchiB1 is probably not exclusively responsible for the increase in cell dry weight and calcofluor fluorescence observed for $\triangle$ PcvelA. Other genes involved in chitin catabolism, such as NagA encoding $\beta-1,4-N$-acetylglucosaminidase (Hoff et al., 2010a; Díez et al., 2005), most probably are also affecting the phenotype of this deletion strain.

Fungal growth with colloidal chitin as the sole carbon and nitrogen source indicated that PcChiB1 activity is not a rate-limiting step in the catabolism of externally supplied chitin. Probably, the remaining activities provided by other chitinases are sufficient to degrade exogenous chitin. An unexpected, and to our knowledge novel, phenotype was detected when the $\triangle P c c h i B 1$ mutant and control strains were grown in media containing GlcNAc as the sole carbon and nitrogen source. Only the knockout mutants and the ancestor strain of the Wisconsin lineage, Q176 (Backus et al., 1946), were able to use the final product of chitin catabolism efficiently. This strain-specific phenotype suggests that the ability to use GlcNAc was lost during a mutagenesis programme that led to the producer strain Wisconsin 54-1255 (Elander, 1983).

In the published sequence of Wisconsin 54-1255, all genes presumed to be involved in GlcNAc catabolism, based on their well-characterized homologues in the yeast C. albicans, are present as intact ORFs (van den Berg et al., 2008; Wendland et al., 2009; Yamada-Okabe et al., 2001). Moreover, transcript levels of the P. chrysogenum homologue of the NAG1 gene showed no strain-specific expression pattern, indicating that GlcNAc catabolism is functional in Wisconsin 54-1255 and its descendants. When the expression of the homologue of $\mathrm{CreA}$, a major regulator of carbon repression in A. nidulans (Arst \& Cove, 1973; Dowzer \& Kelly, 1989), was analysed in response to GlcNAc, increased transcript levels were observed in Q176 and deletion mutants. As indicated by the rescued strain lacking any detectable CreA transcript, increased CreA levels in disruption mutants are a direct or indirect consequence of PcchiB1 deletion.

\section{Chitinase PcChiB1 is associated with the cell wall}

Microscopic analysis of the cellular localization of the PcChiB1-DsRed fusion protein revealed predominant 
fluorescence at the fungal cell wall. To our knowledge, this is the first report of a class $\mathrm{V}$ chitinase associating with the cell wall. However, the primary structure of PcChiB1 contains no detectable motif for directing PcChiB1 to the cell wall: neither a chitin-binding motif, as found in the cell wall-located chitinase CTS1 from Saccharomyces cerevisiae (Kuranda \& Robbins, 1991), nor a glycosylphosphatidylinisotol (GPI) anchor for cell wall localization (Bowman et al., 2006; Li et al., 2007) can be predicted for the PcChiB1 sequence. Since PcChiB1 possesses a signal peptide for secretion (Perlman \& Halvorson, 1983; von Heijne, 1986), we propose that cell wall fluorescence of PcChiB1-DsRed occurs when PcChiB1 is translocated to the cell wall just before being secreted by the secretory pathway of $P$. chrysogenum.

Further understanding of the function of PcChiB1 and other chitinases from $P$. chrysogenum can provide advantages in the fermentation of industrially important filamentous fungi. Manipulation of fungal morphology can contribute to cost-efficient production processes by lowering the energy required for aeration and stirring followed by filtering of fungal cells.

\section{ACKNOWLEDGEMENTS}

We thank Melanie Reininghaus for excellent technical assistance, and Drs Birgit Hoff (BASF SE, Ludwigshafen, Germany) and Rudolf Mitterbauer (Sandoz GmbH, Kundl, Austria) for helpful discussions. This work was funded by Sandoz GmbH (Kundl, Austria) and the Christian Doppler Society (Vienna, Austria).

\section{REFERENCES}

Adams, D. J. (2004). Fungal cell wall chitinases and glucanases. Microbiology 150, 2029-2035.

Arst, H. N., Jr \& Cove, D. J. (1973). Nitrogen metabolite repression in Aspergillus nidulans. Mol Gen Genet 126, 111-141.

Backus, M. P., Stauffer, J. F. \& Johnson, M. J. (1946). Penicillin yields from new mold strains. J Am Chem Soc 68, 152-153.

Bartnicki-Garcia, S. (1973). Fundamental aspects of hyphal morphogenesis. In Microbial Differentiation, pp. 245-267. Edited by J. M. Asworth \& J. E. Smith. London: Cambridge University Press.

Bayram, Ö., Krappmann, S., Ni, M., Bok, J. W., Helmstaedt, K., Valerius, O., Braus-Stromeyer, S., Kwon, N. J., Keller, N. P. \& other authors (2008a). VelB/VeA/LaeA complex coordinates light signal with fungal development and secondary metabolism. Science 320, 1504-1506.

Bayram, Ö., Krappmann, S., Seiler, S., Vogt, N. \& Braus, G. H. (2008b). Neurospora crassa ve-1 affects asexual conidiation. Fungal Genet Biol 45, 127-138.

Bendtsen, J. D., Nielsen, H., von Heijne, G. \& Brunak, S. (2004). Improved prediction of signal peptides: SignalP 3.0. J Mol Biol 340, 783-795.

Bok, J. W. \& Keller, N. P. (2004). LaeA, a regulator of secondary metabolism in Aspergillus spp. Eukaryot Cell 3, 527-535.

Bowman, S. M., Piwowar, A., Al Dabbous, M., Vierula, J. \& Free, S. J. (2006). Mutational analysis of the glycosylphosphatidylinositol (GPI) anchor pathway demonstrates that GPI-anchored proteins are required for cell wall biogenesis and normal hyphal growth in Neurospora crassa. Eukaryot Cell 5, 587-600.

Bradford, M. M. (1976). A rapid and sensitive method for the quantitation of microgram quantities of protein utilizing the principle of protein-dye binding. Anal Biochem 72, 248-254.

Calvo, A. M. (2008). The VeA regulatory system and its role in morphological and chemical development in fungi. Fungal Genet Biol 45, 1053-1061.

Cantarel, B. L., Coutinho, P. M., Rancurel, C., Bernard, T., Lombard, V. \& Henrissat, B. (2009). The Carbohydrate-Active EnZymes database (CAZy): an expert resource for glycogenomics. Nucleic Acids Res 37 (Database issue), D233-D238.

Cary, J. W., OBrian, G. R., Nielsen, D. M., Nierman, W., HarrisCoward, P., Yu, J., Bhatnagar, D., Cleveland, T. E., Payne, G. A. \& Calvo, A. M. (2007). Elucidation of veA-dependent genes associated with aflatoxin and sclerotial production in Aspergillus flavus by functional genomics. Appl Microbiol Biotechnol 76, 1107-1118.

Díez, B., Rodríguez-Sáiz, M., de la Fuente, J. L., Moreno, M. Á. \& Barredo, J. L. (2005). The nagA gene of Penicillium chrysogenum encoding $\beta$-N-acetylglucosaminidase. FEMS Microbiol Lett 242, 257 264.

Donzelli, B. G. \& Harman, G. E. (2001). Interaction of ammonium, glucose, and chitin regulates the expression of cell wall-degrading enzymes in Trichoderma atroviride strain P1. Appl Environ Microbiol 67, 5643-5647.

Dowzer, C. E. \& Kelly, J. M. (1989). Cloning of the creA gene from Aspergillus nidulans: a gene involved in carbon catabolite repression. Curr Genet 15, 457-459.

Dreyer, J., Eichhorn, H., Friedlin, E., Kürnsteiner, H. \& Kück, U. (2007). A homologue of the Aspergillus velvet gene regulates both cephalosporin C biosynthesis and hyphal fragmentation in Acremonium chrysogenum. Appl Environ Microbiol 73, 3412-3422.

Elander, R. (1983). Strain improvement and preservation of betalactam producing microorganisms. In Antibiotics Containing the BetaLactam Structure I, pp. 97-146. Edited by A. L. Demain \& N. Solomon. Berlin, Heidelberg, New York: Springer-Verlag.

Elorza, M. V., Rico, H. \& Sentandreu, R. (1983). Calcofluor white alters the assembly of chitin fibrils in Saccharomyces cerevisiae and Candida albicans cells. J Gen Microbiol 129, 1577-1582.

Escott, G. M., Hearn, V. M. \& Adams, D. J. (1998). Inducible chitinolytic system of Aspergillus fumigatus. Microbiology 144, 1575-1581.

Felsenstein, J. (2005). PHYLIP (Phylogeny Inference Package) version 3.6. Distributed by the author. Department of Genome Sciences, University of Washington, Seattle, WA, USA.

Gooday, G. W., Zhu, W. Y. \& O'Donnell, R. W. (1992). What are the roles of chitinases in the growing fungus? FEMS Microbiol Lett $\mathbf{1 0 0}$, 387-391.

Gruber, S., Vaaje-Kolstad, G., Matarese, F., López-Mondéjar, R., Kubicek, C. P. \& Seidl-Seiboth, V. (2011). Analysis of subgroup C of fungal chitinases containing chitin-binding and LysM modules in the mycoparasite Trichoderma atroviride. Glycobiology 21, 122-133.

Haas, H., Angermayr, K., Zadra, I. \& Stöffler, G. (1997). Overexpression of $n r e B$, a new GATA factor-encoding gene of Penicillium chrysogenum, leads to repression of the nitrate assimilatory gene cluster. J Biol Chem 272, 22576-22582.

Henrissat, B. \& Bairoch, A. (1993). New families in the classification of glycosyl hydrolases based on amino acid sequence similarities. Biochem J 293, 781-788.

Hoff, B., Pöggeler, S. \& Kück, U. (2008). Eighty years after its discovery, Fleming's Penicillium strain discloses the secret of its sex. Eukaryot Cell 7, 465-470. 
Hoff, B., Kamerewerd, J., Sigl, C., Mitterbauer, R., Zadra, I., Kürnsteiner, H. \& Kück, U. (2010a). Two components of a velvetlike complex control hyphal morphogenesis, conidiophore development, and penicillin biosynthesis in Penicillium chrysogenum. Eukaryot Cell 9, 1236-1250.

Hoff, B., Kamerewerd, J., Sigl, C., Zadra, I. \& Kück, U. (2010b). Homologous recombination in the antibiotic producer Penicillium chrysogenum: strain $\triangle$ Pcku70 shows up-regulation of genes from the HOG pathway. Appl Microbiol Biotechnol 85, 1081-1094.

Horton, P., Park, K. J., Obayashi, T., Fujita, N., Harada, H., AdamsCollier, C. J. \& Nakai, K. (2007). WoLF PSORT: protein localization predictor. Nucleic Acids Res 35 (Web Server issue), W585-W587.

Jaques, A. K., Fukamizo, T., Hall, D., Barton, R. C., Escott, G. M., Parkinson, T., Hitchcock, C. A. \& Adams, D. J. (2003). Disruption of the gene encoding the ChiB1 chitinase of Aspergillus fumigatus and characterization of a recombinant gene product. Microbiology 149, 2931-2939.

Jerpseth, B., Greener, A., Short, J. M., Viola, J. \& Kretz, P. L. (1992). XL1-Blue $\mathrm{MRF}^{\prime}$ E. coli cells: $\mathrm{McrA}^{-}, \mathrm{McrCB}^{-}, \mathrm{McrF}^{-}, \mathrm{Mrr}^{-}, \mathrm{HsdR}^{-}$ derivative of XL1-Blue cells. Strateg Mol Biol 5, 81-83.

Kubodera, T., Yamashita, N. \& Nishimura, A. (2000). Pyrithiamine resistance gene ( $p t r A)$ of Aspergillus oryzae: cloning, characterization and application as a dominant selectable marker for transformation. Biosci Biotechnol Biochem 64, 1416-1421.

Kuranda, M. J. \& Robbins, P. W. (1991). Chitinase is required for cell separation during growth of Saccharomyces cerevisiae. J Biol Chem 266, 19758-19767.

Li, S., Myung, K., Guse, D., Donkin, B., Proctor, R. H., Grayburn, W. S. \& Calvo, A. M. (2006). FvVE1 regulates filamentous growth, the ratio of microconidia to macroconidia and cell wall formation in Fusarium verticillioides. Mol Microbiol 62, 1418-1432.

Li, H., Zhou, H., Luo, Y., Ouyang, H., Hu, H. \& Jin, C. (2007). Glycosylphosphatidylinositol (GPI) anchor is required in Aspergillus fumigatus for morphogenesis and virulence. Mol Microbiol 64, 1014-1027.

Lopes, M. A., Gomes, D. S., Koblitz, M. G., Pirovani, C. P., Cascardo, J. C., Góes-Neto, A. \& Micheli, F. (2008). Use of response surface methodology to examine chitinase regulation in the basidiomycete Moniliophthora perniciosa. Mycol Res 112, 399-406.

Mach, R. L., Peterbauer, C. K., Payer, K., Jaksits, S., Woo, S. L., Zeilinger, S., Kullnig, C. M., Lorito, M. \& Kubicek, C. P. (1999). Expression of two major chitinase genes of Trichoderma atroviride ( $T$. harzianum P1) is triggered by different regulatory signals. Appl Environ Microbiol 65, 1858-1863.

Maeda, H. \& Ishida, N. (1967). Specificity of binding of hexopyranosyl polysaccharides with fluorescent brightener. J Biochem 62, 276-278.

Minuth, W., Tudzynski, P. \& Esser, K. (1982). Extrachromosomal genetics of Cephalosporium acremonium. Curr Genet 5, 227-231.

Mullaney, E. J., Hamer, J. E., Roberti, K. A., Yelton, M. M. \& Timberlake, W. E. (1985). Primary structure of the $\operatorname{trp} C$ gene from Aspergillus nidulans. Mol Gen Genet 199, 37-45.

Natarajan, K. \& Datta, A. (1993). Molecular cloning and analysis of the NAG1 cDNA coding for glucosamine-6-phosphate deaminase from Candida albicans. J Biol Chem 268, 9206-9214.

Nicholas, K. B., Nicholas, H. B. \& Deerfield, D. W., II (1997). GeneDoc: analysis and visualization of genetic variation. EMBNEW NEWS 4, 14.

Page, R. D. (1996). TreeView: an application to display phylogenetic trees on personal computers. Comput Appl Biosci 12, 357-358.

Pearson, C. L., Xu, K., Sharpless, K. E. \& Harris, S. D. (2004). MesA, a novel fungal protein required for the stabilization of polarity axes in Aspergillus nidulans. Mol Biol Cell 15, 3658-3672.
Pedersen, A. G. \& Nielsen, H. (1997). Neural network prediction of translation initiation sites in eukaryotes: perspectives for EST and genome analysis. Proc Int Conf Intell Syst Mol Biol 5, 226-233.

Perlman, D. \& Halvorson, H. O. (1983). A putative signal peptidase recognition site and sequence in eukaryotic and prokaryotic signal peptides. J Mol Biol 167, 391-409.

Perrin, R. M., Fedorova, N. D., Bok, J. W., Cramer, R. A., Wortman, J. R., Kim, H. S., Nierman, W. C. \& Keller, N. P. (2007). Transcriptional regulation of chemical diversity in Aspergillus fumigatus by LaeA. PLoS Pathog 3, e50.

Pócsi, I., Leiter, E., Kwon, N. J., Shin, K. S., Kwon, G. S., Pusztahelyi, T., Emri, T., Abuknesha, R. A., Price, R. G. \& Yu, J. H. (2009). Asexual sporulation signalling regulates autolysis of Aspergillus nidulans via modulating the chitinase ChiB production. J Appl Microbiol 107, 514-523.

Punt, P. J., Dingemanse, M. A., Kuyvenhoven, A., Soede, R. D., Pouwels, P. H. \& van den Hondel, C. A. (1990). Functional elements in the promoter region of the Aspergillus nidulans gpdA gene encoding glyceraldehyde-3-phosphate dehydrogenase. Gene 93, 101-109.

Pusztahelyi, T., Molnár, Z., Emri, T., Klement, É., Miskei, M., Kerékgyárto, J., Balla, J. \& Pócsi, I. (2006). Comparative studies of differential expression of chitinolytic enzymes encoded by chiA, chiB, chiC and nagA genes in Aspergillus nidulans. Folia Microbiol (Praha) 51, 547-554.

Rast, D. M., Horsch, M., Furter, R. \& Gooday, G. W. (1991). A complex chitinolytic system in exponentially growing mycelium of Mucor rouxii: properties and function. J Gen Microbiol 137, 2797-2810.

Ruijter, J. M., Ramakers, C., Hoogaars, W. M., Karlen, Y., Bakker, O., van den Hoff, M. J. \& Moorman, A. F. (2009). Amplification efficiency: linking baseline and bias in the analysis of quantitative PCR data. Nucleic Acids Res 37, e45.

Sahai, A. S. \& Manocha, M. S. (1993). Chitinases of fungi and plants: their involvement in morphogenesis and host-parasite interaction. FEMS Microbiol Rev 11, 317-338.

Sambrook, J. \& Russell, D. W. (2001). Molecular Cloning: a Laboratory Manual, 3rd edn. Cold Spring Harbor, NY: Cold Spring Harbor Laboratory.

Sarikaya Bayram, Ö., Bayram, Ö., Valerius, O., Park, H. S., Irniger, S., Gerke, J., Ni, M., Han, K. H., Yu, J. H. \& Braus, G. H. (2010). LaeA control of velvet family regulatory proteins for light-dependent development and fungal cell-type specificity. PLoS Genet 6, e1001226.

Seidl, V. (2008). Chitinases of filamentous fungi: a large group of diverse proteins with multiple physiological functions. Fungal Biol Rev 22, 36-42.

Seidl, V., Huemer, B., Seiboth, B. \& Kubicek, C. P. (2005). A complete survey of Trichoderma chitinases reveals three distinct subgroups of family 18 chitinases. FEBS J 272, 5923-5939.

Shin, K. S., Kwon, N. J., Kim, Y. H., Park, H. S., Kwon, G. S. \& Yu, J. H. (2009). Differential roles of the ChiB chitinase in autolysis and cell death of Aspergillus nidulans. Eukaryot Cell 8, 738-746.

Takeshita, N., Higashitsuji, Y., Konzack, S. \& Fischer, R. (2008). Apical sterol-rich membranes are essential for localizing cell end markers that determine growth directionality in the filamentous fungus Aspergillus nidulans. Mol Biol Cell 19, 339-351.

Thompson, J. D., Gibson, T. J., Plewniak, F., Jeanmougin, F. \& Higgins, D. G. (1997). The CLUSTAL_X windows interface: flexible strategies for multiple sequence alignment aided by quality analysis tools. Nucleic Acids Res 25, 4876-4882.

van den Berg, M. A., Albang, R., Albermann, K., Badger, J. H., Daran, J. M., Driessen, A. J., Garcia-Estrada, C., Fedorova, N. D., Harris, D. M. \& other authors (2008). Genome sequencing and analysis of the filamentous fungus Penicillium chrysogenum. Nat Biotechnol 26, 11611168. 
von Heijne, G. (1986). A new method for predicting signal sequence cleavage sites. Nucleic Acids Res 14, 4683-4690.

Wendland, J., Schaub, Y. \& Walther, A. (2009). N-Acetylglucosamine utilization by Saccharomyces cerevisiae based on expression of Candida albicans NAG genes. Appl Environ Microbiol 75, 5840-5845.

Wiemann, P., Brown, D. W., Kleigrewe, K., Bok, J. W., Keller, N. P., Humpf, H. U. \& Tudzynski, B. (2010). FfVel1 and FfLae1, components of a velvet-like complex in Fusarium fujikuroi, affect differentiation, secondary metabolism and virulence. Mol Microbiol 77, 972-994.

Wirth, S. J. \& Wolf, G. A. (1990). Dye-labelled substrates for the assay and detection of chitinase and lysozyme activity. J Microbiol Methods 12, 197-205.
Yamada-Okabe, T., Sakamori, Y., Mio, T. \& Yamada-Okabe, H. (2001). Identification and characterization of the genes for $\mathrm{N}$ acetylglucosamine kinase and $\mathrm{N}$-acetylglucosamine-phosphate deacetylase in the pathogenic fungus Candida albicans. Eur J Biochem 268, 2498-2505.

Yamazaki, H., Yamazaki, D., Takaya, N., Takagi, M., Ohta, A. \& Horiuchi, H. (2007). A chitinase gene, chiB, involved in the autolytic process of Aspergillus nidulans. Curr Genet 51, 89-98.

Zdobnov, E. M. \& Apweiler, R. (2001). InterProScan - an integration platform for the signature-recognition methods in InterPro. Bioinformatics 17, 847-848.

Edited by: S. D. Harris 